\title{
Review Article \\ The Role of BRCA2 Mutation Status as Diagnostic, Predictive, and Prognosis Biomarker for Pancreatic Cancer
}

\author{
Javier Martinez-Useros and Jesus Garcia-Foncillas \\ Translational Oncology Division, Oncohealth Institute, Health Research Institute, University Hospital Fundación Jiménez Díaz-UAM, \\ Madrid, Spain
}

Correspondence should be addressed to Javier Martinez-Useros; javier.museros@oncohealth.eu

Received 8 August 2016; Revised 21 November 2016; Accepted 28 November 2016

Academic Editor: Renato Franco

Copyright (C) 2016 J. Martinez-Useros and J. Garcia-Foncillas. This is an open access article distributed under the Creative Commons Attribution License, which permits unrestricted use, distribution, and reproduction in any medium, provided the original work is properly cited.

\begin{abstract}
Pancreatic cancer is one of the deadliest cancers worldwide, and life expectancy after diagnosis is often short. Most pancreatic tumours appear sporadically and have been highly related to habits such as cigarette smoking, high alcohol intake, high carbohydrate, and sugar consumption. Other observational studies have suggested the association between pancreatic cancer and exposure to arsenic, lead, or cadmium. Aside from these factors, chronic pancreatitis and diabetes have also come to be considered as risk factors for these kinds of tumours. Studies have found that $10 \%$ of pancreatic cancer cases arise from an inherited syndrome related to some genetic alterations. One of these alterations includes mutation in BRCA2 gene. BRCA2 mutations impair DNA damage response and homologous recombination by direct regulation of RAD51. In light of these findings that link genetic factors to tumour development, DNA damage agents have been proposed as target therapies for pancreatic cancer patients carrying $B R C A 2$ mutations. Some of these drugs include platinum-based agents and PARP inhibitors. However, the acquired resistance to PARP inhibitors has created a need for new chemotherapeutic strategies to target BRCA2. The present systematic review collects and analyses the role of $B R C A 2$ alterations to be used in early diagnosis of an inherited syndrome associated with familiar cancer and as a prognostic and predictive biomarker for the management of pancreatic cancer patients.
\end{abstract}

\section{Introduction}

In 1994, BRCA2 (breast cancer gene 2) was located in chromosome 13ql2-13 by the group led by Wooster et al. [1]. Transmission of this gene follows an autosomal dominant pattern with incomplete penetrance [2]. Soon thereafter, BRCA2 was reported as a tumour suppressor gene based on evidence of loss of heterozygosity in 7 out of 8 familial breast cancers [3]. Subsequently, BRCA2 was associated with high-risk breast and ovarian cancer with a large component of heritability [47], although the risk for ovarian cancer due to $B R C A 2$ is much lower than the risk associated with $B R C A 1$ [8].

Only one year after this gene was discovered, the association between BRCA2 and pancreatic cancer was assessed by Schutte et al. [9]. It was found that pancreatic cancer appeared in some individuals with a history of familial breast cancer associated with BRCA2 alterations [10]; thus, it was estimated that $10 \%$ of cases of pancreatic cancer have an underlying inherited component $[11,12]$.
Worldwide pancreatic cancer incidence has increased from 185,000 in the 1980 s [13] to 227,000 cases per year in 2014 [14]. In 2007, the highest incidence of pancreatic cancer was in the Baltic countries and central and eastern Europe. In northern European countries and the UK, this cancer has risen over most recent years and is rising in countries of southern, central, and eastern Europe [15]. It is hypothesised that this increase could be associated with increased consumption of high-sugar or carbohydrate-rich foods [16] or simply reflects the ageing of the population in recent decades.

Nowadays, the primary acquired risk factors for pancreatic cancer are cigarette smoking $(\mathrm{HR}=1.74)$, high alcohol consumption $(\mathrm{HR}=1.1-1.5)$, obesity (body mass index > 30; HR =1.2-1.5), and some infectious diseases that include Helicobacter pylori $(H R=1.5)$, Hepatitis B virus, or Human Immunodeficiency virus [17-19]. Interestingly, other studies suggested that heavy consumption of cooking and table salt appeared to be significantly associated with pancreatic cancer 


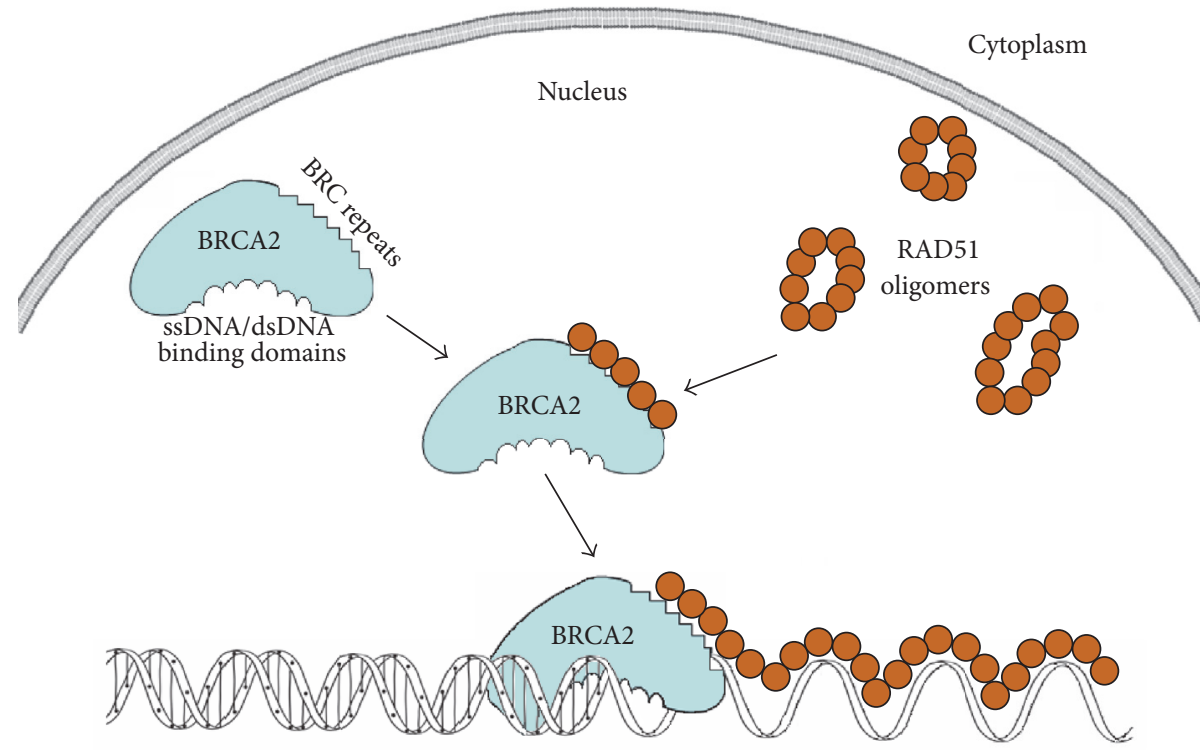

FIGURE 1: DNA damage response model performed by BRCA2 and RAD51. Dephosphorylation of BRCA2 at Ser3291 enables RAD51 binding to BRCA2 in BRC repeats and the subsequent binding to double-strand DNA. RAD51 oligomers bind to single-strand DNA at the site of damage that enables its repairs.

( $P=0.009$ and $P=0.0001$, resp.), and a similar correlation was found with smoked food $(P<0.01)[20]$.

Interestingly, observational studies link pancreatic cancer incidence to cadmium, arsenic, and lead exposure [21]. The countries with the highest levels of arsenic (more than $10 \mu \mathrm{g} / \mathrm{L}$, values recommended by the World Health Organization [22]) are those with highest incidence of pancreatic cancer. These countries include Baltic countries (especially Finland) and central and eastern European countries such as Austria, Czech Republic, Slovakia, and Hungary [23].

Pancreatic cancer has long been related to family history of pancreatic cancer $(\mathrm{HR}=2.20,95 \% ; \mathrm{CI}=1.16-4.19)$ and melanoma $(\mathrm{HR}=1.74,95 \%$; $\mathrm{CI}=1.03-2.95)$, upon breast, ovarian, lung, gastrointestinal, or prostate cancer [24]. In addition, diabetes has also been associated with pancreatic cancer $(\mathrm{HR}=1.4-2.2)[25]$.

Surgical resection is currently the best option so far to improve survival [26]. Mean life expectancy for pancreatic cancer is 1.4 years reaching 3.5 years for surgically resected patients versus 0.8 years for nonoperated patients $(P<$ 0.001) [27]. However, cancers of the pancreas are usually asymptomatic, and the disease only becomes apparent after the tumour invades surrounding tissues or metastasises to distant organs [28]. As a result, there is a pressing need to find new approaches and strategies; of these, targeted therapies hold particular promise, and BRCA2 is one such therapy that has great potential. BRCA2 regulates sister chromatid cohesion and/or alignment [29] and plays a key role in response to DNA damage by direct regulation of RAD51 recombination (Figure 1).

\section{BRCA2 in DNA Damage Response}

The first attempt to associate BRCA2 with DNA damage response was as a cofactor associated with human RAD51- dependent DNA repair of double-strand breaks through 8 evolutionarily conserved BRC motifs encoded in exon 11 of BRCA2 (Figure 1) [30]. The milestone of DNA strand exchange is RAD51 protein which is closely related to other tumour suppressor genes such as TP53, ATM, BRCA1, BLM, and FANCD2. Preclinical studies showed that BRCA2 disruptions sensitize mice embryos to ionising radiation [30], which was previously observed in RAD51 knockout mice embryos [31]. Furthermore, mice carrying truncations on BRCA2 loci were one-third smaller than their wild-type littermates and had improper tissue differentiation, sterility, and a shorter overall survival $[32,33]$.

On the other hand, BRCA2 is essential for repair of double-strand breaks by homologous recombination [34]. BRCA2 alterations led to elevated P53 and P21 expression, spontaneous accumulation of chromosomal abnormalities, and aberrant chromatid exchanges, which suggests its role in pancreatic tumorigenesis (Figure 2). The aforementioned properties make BRCA2 a crucial factor to maintain cell homeostasis.

\section{BRCA2 as a Prognostic Biomarker of Pancreatic Cancer}

$B R C A 2$ inactivation is due mainly to genomic mutations. The most common mutations of BRCA2 found in pancreatic cancer patients are 6174delT frameshift mutation, 6158ins T mutation, splice site mutation 16-2A > G, and the splice site mutation $15-1 G>A[35,36]$. Another variant located in the $3^{\prime}$-untranslated region is significantly associated with lower expression of brca2 RNA and, consequently, with sporadic pancreatic cancer $(\mathrm{HR}=1.3 ; P<0.0001)$ [37]. BRCA2 inactivation has been reported to be a late event in sporadic pancreatic tumorigenesis [38] preceded by KRAS mutation 


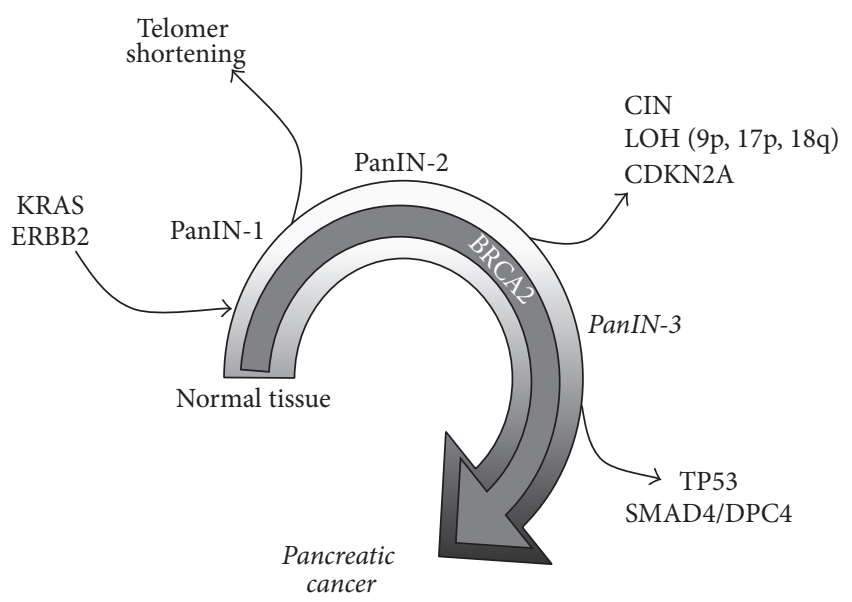

FIGURE 2: Transformation model of familiar pancreatic adenocarcinoma. Ingoing arrows concern oncogenic effectors that are acquired in the cancer progression. Outgoing arrows highlight tumour suppressor factors that become inactivated in pancreatic cancer. PanIN: pancreatic intraepithelial neoplasia; CIN: chromosome instability; LOH: loss of heterozygosity.

(G12D) or loss of TP53 [39, 40]. Overall, BRCA2 could be used to determine patient prognosis.

Ashkenazi Jews have been one of the most closely studied ethnic groups concerning the significance of BRCA2 mutations and family involved pancreatic cancer. Struewing et al. found that $>90 \%$ of Ashkenazi patients that carried BRCA2 mutations detected in blood sample showed an association with increased risk of pancreatic cancer [41]. The 6174delT mutation of BRCA2 was determined to be present in $1 \%(\mathrm{CI}=$ 0.6-1.5) of 1.255 Jewish individuals [42]. Another study performed with 26 European families reported that $19 \%$ (CI = $7 \%$ to $39 \%$ ) of the families with first-degree relatives with pancreatic cancer had either a mutation or a splice variant of $B R C A 2$ [43]. Murphy et al. reported $17 \%$ of BRCA2 mutations in 31 samples from pancreatic cancer patients with at least two first-degree relatives affected by pancreatic cancer [35]. One study found $6 \%$ (10 of 180 families) with BRCA2 mutation and moderate or high-risk pancreatic cancer predisposition and $6 \%$ (8 of 146) of families that presented two or more firstdegree relatives affected with pancreatic cancer [44].

This kind of studies performed with high-risk pancreatic cancer families provides a true enlightenment of $B R C A 2$ associated pancreatic cancer; however, $B R C A 2$ has not been directly related to patient outcome.

Pancreatic cancers with a high familial component are associated with mutations not only in BRCA2 but also in ATM, CDKN2, PALB2, PRSS1, STK11, or mismatch repair (MMR) family genes [45]. MMR genes allow continuous point mutations in repeats regions of DNA known as microsatellites that become unstable. Alterations in microsatellites are found in oncogenes associated with initiation and progression of cancer [46]. Several MMR genes are involved in the acquisition of aggressive phenotype of cancer [47]. For example, alterations on EXO1, MLH1, MSH2, MSH3, MSH6, PMS2, PMS2L3, RECQL, TP73, and TREX1 were statistically significantly associated with overall survival of pancreatic cancer patients [48]. Nevertheless, the predisposition to pancreatic cancer by MMR family genes is due mainly to mutations in $\mathrm{MLH1}$ and $\mathrm{MSH} 2$ and it is estimated to be $<5 \%$ [49].

\section{BRCA2 as Predictive Biomarker in Pancreatic Cancer}

BRCA2 mutations impair DNA repair; thus, they are considered biomarkers of genomic instability and DNA damage repair deficiency. Therefore, $B R C A 2$ mutations could be used as predictive biomarkers of response to some DNA damage agents. Some of these compounds include platinum-based agents and PARP inhibitors. They are considered targeted therapies indicated for BRCA2-positive tumours according to some good results achieved in clinical trials [50]. Platinumbased drugs are, despite their toxicity, one of the goldstandard chemotherapies administered to pancreatic cancer patients. Cisplatin, carboplatin, and oxaliplatin are some of the mostly used in clinical practice and allow cross-linking and forming DNA adducts which trigger apoptosis cascade [51].

Oliver et al. presented a cohort of pancreatic cancer patients; of them, those with family history of breast, ovarian, or pancreatic cancers showed significantly increased survival after platinum-based chemotherapy compared to other patients without family history ( 22.9 versus 6.3 months, $P<0.01$ ) [52]. A case report of a 60-year-old pancreatic adenocarcinoma patient carrying the BRCA2 mutation, 1153insertionT, presented recurrence after gemcitabine treatment but showed a complete response after cisplatin and gemcitabine as second-line therapy [53]. Subsequently, another study with pancreatic cancer patients with positive $B R C A 1 / 2$ mutations showed improved outcome after treatment with platinum-based chemotherapy. Here, patients with locally advanced disease were pathologically downstaged and those with metastatic disease had significant increase in their progression-free survival [54]. Golan et al. reported that stage III/IV patients treated with platinum-based chemotherapy carrying $B R C A 1 / 2$ mutations had improved overall survival compared to those patients treated with other drugs (22 versus 9 months, resp.; $P=0.039$ ) [55]. One study reported that 5 out of 8 patients with pancreatic ductal adenocarcinomas that were treated with platinum-based chemotherapy presented $B R C A 2$ mutation. Of these 5 patients, 2 had complete radiological response and 2 had partial responses to platinum treatment [56]. All the above-mentioned studies suggest that $B R C A 2$ mutations predict not only platinum response but also better outcome and longer survival for pancreatic cancer patients with advanced disease.

Poly(ADP-ribose) polymerase inhibitors (PARPi) prevent the repair of double-strand DNA breaks, homologous recombination, and replication repair performed by the PARP family of proteins [57]. A preclinical study with CAPAN-1 cell line has suggested that 6174delT mutation of BRCA2 is highly sensitive to PARPi [58]. However, another study also performed with pancreatic cancer cell lines reported how a PARPi increases sensitivity to chemoradiotherapy independently of BRCA2 mutation status [59]. 
TABLE 1: Clinical trials for $B R C A 2$ mutated pancreatic cancer patients.

\begin{tabular}{|c|c|c|c|c|c|}
\hline Clinical trial & Phase & Study type & Drugs & Sponsor & Inclusion criteria \\
\hline \multirow{7}{*}{ NCT02309632 } & \multirow{7}{*}{ Screening } & \multirow{7}{*}{ Nonrandomized } & \multirow{7}{*}{$\begin{array}{l}\text { Screening of } \\
\text { high-risk } \\
\text { individuals }\end{array}$} & \multirow{7}{*}{ University of Arkansas } & Peutz-Jegher's Syndrome \\
\hline & & & & & BRCA1 mutation carrier \\
\hline & & & & & BRCA2 mutation carrier \\
\hline & & & & & Ataxia-telangiectasia \\
\hline & & & & & $\begin{array}{l}\text { Familial atypical malignant } \\
\text { melanoma syndrome }\end{array}$ \\
\hline & & & & & $\begin{array}{l}\text { Colorectal neoplasms, } \\
\text { hereditary nonpolyposis }\end{array}$ \\
\hline & & & & & Hereditary pancreatitis \\
\hline \multirow{5}{*}{ NCT02000089 } & \multirow{5}{*}{$\begin{array}{l}\text { Prospective } \\
\text { observational }\end{array}$} & \multirow{5}{*}{ Cohort } & \multirow{5}{*}{$\begin{array}{l}\text { Human synthetic } \\
\text { secretin }\end{array}$} & \multirow{5}{*}{$\begin{array}{l}\text { Johns Hopkins } \\
\text { University }\end{array}$} & Pancreas cancer \\
\hline & & & & & Peutz-Jeghers Syndrome \\
\hline & & & & & Gene mutation \\
\hline & & & & & Germline mutation carrier \\
\hline & & & & & Lynch Syndrome \\
\hline \multirow{6}{*}{ NCT02775461 } & \multirow{6}{*}{$\begin{array}{l}\text { Prospective } \\
\text { observational }\end{array}$} & \multirow{6}{*}{ Cohort } & \multirow{6}{*}{-} & \multirow{6}{*}{$\begin{array}{c}\text { Icahn School of } \\
\text { Medicine at Mount Sinai }\end{array}$} & Pancreas cancer \\
\hline & & & & & Pancreatitis \\
\hline & & & & & Chronic pancreatitis \\
\hline & & & & & Pancreatic cyst \\
\hline & & & & & $\begin{array}{l}\text { Family history of pancreas } \\
\text { cancer }\end{array}$ \\
\hline & & & & & Genetic mutations \\
\hline \multirow{7}{*}{ NCT01585805 } & \multirow{7}{*}{ Phase II } & \multirow{7}{*}{ Randomized } & \multirow{7}{*}{$\begin{array}{c}\text { Gemcitabine, } \\
\text { cisplatin with or } \\
\text { without veliparib } \\
\text { or veliparib alone }\end{array}$} & \multirow{7}{*}{$\begin{array}{l}\text { National Cancer } \\
\text { Institute }\end{array}$} & BRCA1 mutation carrier \\
\hline & & & & & BRCA2 mutation carrier \\
\hline & & & & & $\begin{array}{l}\text { Metastatic pancreatic } \\
\text { adenocarcinoma }\end{array}$ \\
\hline & & & & & Pancreatic adenocarcinoma \\
\hline & & & & & $\begin{array}{c}\text { Recurrent pancreatic } \\
\text { carcinoma }\end{array}$ \\
\hline & & & & & Stage III pancreatic cancer \\
\hline & & & & & Stage IV pancreatic cancer \\
\hline \multirow{2}{*}{ NCT01102569 } & \multirow{2}{*}{$\begin{array}{l}\text { Prospective } \\
\text { observational }\end{array}$} & \multirow{2}{*}{ Cohort } & \multirow{2}{*}{-} & Columbia University & BRCA1 mutation carrier \\
\hline & & & & & BRCA2 mutation carrier \\
\hline NCT00438906 & Prospective & Cohort & Human synthetic & Johns Hopkins & Pancreatic neoplasm \\
\hline NC100430900 & observational & Conort & secretin & University & Peutz-Jeghers Syndrome \\
\hline & & & Veliparib, & & Advanced solid tumors \\
\hline NCT01233505 & Phase I & Interventional & oxaliplatin, & $\begin{array}{l}\text { National Cancer } \\
\text { Institute }\end{array}$ & BRCA1 mutation carrier \\
\hline & & & capecitabine & & BRCA2 mutation carrier \\
\hline & & & & & Peutz-Jeghers Syndrome \\
\hline & & & & & Familial pancreas cancer \\
\hline NCT02703545 & $\begin{array}{l}\text { Prospective } \\
\text { observational }\end{array}$ & Cohort & - & $\begin{array}{l}\text { Jonns Hopkins } \\
\text { University }\end{array}$ & BRCA1 mutation carrier \\
\hline & & & & & BRCA2 mutation carrier \\
\hline & & & & & Hereditary pancreatitis \\
\hline & Prospective & & & Sidney Kimmel & Early pancreatic neoplasia \\
\hline NCT00714701 & observational & Cohort & - & $\begin{array}{l}\text { Comprehensive Cancer } \\
\text { Center }\end{array}$ & Familial pancreatic neoplasia \\
\hline & & & & & Advanced solid tumors \\
\hline & & & & & BRCA1 mutation carrier \\
\hline NCT00892736 & Phase I & Interventional & Veliparib & Institute & BRCA2 mutation carrier \\
\hline & & & & & Estrogen receptor negative \\
\hline & & & & & HER2/Neu negative \\
\hline
\end{tabular}


TABle 1: Continued.

\begin{tabular}{|c|c|c|c|c|c|}
\hline Clinical trial & Phase & Study type & Drugs & Sponsor & Inclusion criteria \\
\hline \multirow{3}{*}{ NCT01339650 } & \multirow{3}{*}{ Phase I } & \multirow{3}{*}{ Interventional } & \multirow{3}{*}{ ABT-767 } & \multirow{3}{*}{ AbbVie } & Advanced solid tumors \\
\hline & & & & & BRCA1 mutation carrier \\
\hline & & & & & BRCA2 mutation carrier \\
\hline \multirow{3}{*}{ NCT01078662 } & \multirow{3}{*}{ Phase II } & \multirow{3}{*}{ Interventional } & \multirow{3}{*}{ Olaparib } & \multirow{3}{*}{ AstraZeneca } & Advanced solid tumors \\
\hline & & & & & BRCA1 mutation carrier \\
\hline & & & & & BRCA2 mutation carrier \\
\hline
\end{tabular}

A different drug popularly used in pancreatic cancer treatment is gemcitabine and is able to induce DNA damage response and PARP degradation [60]. Gemcitabine in combination with PARPi showed promising antitumor activity compared to PBS, gemcitabine, or PARPi alone, in in vivo models of pancreatic cancer [61].

In clinical studies, BRCA2-positive status has been associated with better response to PARPi alone or in combination with other drugs. In one study, 3 out of 4 patients with a known $B R C A 1$ or BRCA2 mutation showed partial response after receiving PARPi alone or in combination with platinumbased chemotherapy [62]. In a phase I/II trial of PARPi in combination with $5 \mathrm{FU}$ and oxaliplatin that included 2 patients with $B R C A 2$ mutation, one showed a partial response and the other achieved complete response [63]. Another phase IB trial of PARPi in combination with gemcitabine and platinum-based chemotherapy reported that BRCA-mutated patients achieved partial response in $56 \%$ and stable disease in $44 \%$ of cases. However, $62 \%$ of $B R C A$ wild-type patients remained with stable disease and $25 \%$ with progression [64].

To date, personalised therapies in pancreatic cancer could improve patient survival if assisted by breakthrough techniques used in molecular diagnosis. Deep sequencing currently offers a high-throughput method of dissecting the underlying mechanisms of tumorigenicity, leading to new strategies for personalised medicine. However, pancreatic cancer genotype is highly heterogeneous, and this heterogeneity involves its therapeutic ineffectiveness [65]. The IMPaCT clinical trial was set out to improve patient survival using deep sequencing to guide treatment decisions. In the study, patients carrying BRCA2 mutations were eligible to receive targeted treatment based on 5FU and mitomycin versus gemcitabine alone [66]. Nevertheless, no consistent conclusions arose from this trial due to the low number of patients recruited with $B R C A 2$ mutations [67].

Nevertheless, patients could present acquired resistance to platinum-based chemotherapy by accumulation of secondary genomic alterations, such as $B C R-A B L$ point mutations, in which case the $B R C A 2$ mutation effect is bypassed [68].

Table 1 summarises ongoing or recently completed clinical trials recruiting $B R C A 2$ mutated pancreatic cancer patients.

\section{Conclusions}

Pancreatic cancer is one of the most deadly cancers worldwide, and despite new methods of early diagnosis, surgery, and drug discovery, tumour cells tend to scatter and metastasise to vital organs, thereby reducing survival significantly. It is also highly resistant to treatments and responds poorly to chemoradiotherapy; indeed, chemoradiotherapy is used in most of cases as a palliative therapy. Therefore, patients are encouraged to participate in clinical trials regardless of disease stage.

Some studies attribute the increasing incidence of sporadic pancreatic cancer to the ageing of the population. However, several studies have reported different factors associated with this neoplasm. Obesity, cigarette smoking, high alcohol intake, and chronic pancreatitis are the most relevant factors [69].

On the other hand, it is estimated that $10 \%$ of pancreatic cancer cases are due to an inherited syndrome [11, 12] caused by mutations in the BRCA1 or BRCA2 genes [10]. Most of the clinical studies that relate pancreatic cancer to BRCA2 mutations have been performed on Ashkenazim. Although this fact limits the findings' applicability to other populations, there is nonetheless great potential in the study of the heritability of BRCA2 mutation and pancreatic cancer incidence [41, 42].

Several preclinical and clinical studies have suggested the potential use of BRCA2 mutations as biomarkers for DNA damage agents' response like platinum-based chemotherapy and PARPi. Clinical trials have evaluated BRCA2 as a predictive biomarker for use in platinum-based therapies but they were mainly retrospective and with a scarce cohort of patients. Thus, further multicenter prospective studies using larger cohorts are required to investigate multitarget therapies and their potential to minimize resistance to therapy.

\section{Competing Interests}

The authors declare no conflict of interests.

\section{Acknowledgments}

The authors thank Oliver Shaw (IIS-FJD) for editing the manuscript for English usage, clarity, and style.

\section{References}

[1] R. Wooster, S. L. Neuhausen, J. Mangion et al., "Localization of a breast cancer susceptibility gene, BRCA2, to chromosome 13q12-13," Science, vol. 265, no. 5181, pp. 2088-2090, 1994.

[2] D. L. Thull and V. G. Vogel, "Recognition and management of hereditary breast cancer syndromes," Oncologist, vol. 9, no. 1, pp. 13-24, 2004. 
[3] N. Collins, R. McManus, R. Wooster et al., "Consistent loss of the wild type allele in breast cancers from a family linked to the BRCA2 gene on chromosome 13q12-13," Oncogene, vol. 10, no. 8, pp. 1673-1675, 1995.

[4] H. T. Lynch, P. Watson, S. Tinley et al., "An update on DNAbased BRCA1/BRCA2 genetic counseling in hereditary breast cancer," Cancer Genetics and Cytogenetics, vol. 109, no. 2, pp. 9198, 1999.

[5] C. E. Bronner, S. M. Baker, P. T. Morrison et al., "Mutation in the DNA mismatch repair gene homologue $h M L H 1$ is associated with hereditary non-polyposis colon cancer," Nature, vol. 368, no. 6468 , pp. 258-261, 1994.

[6] K. A. Foster, P. Harrington, J. Kerr et al., "Somatic and germline mutations of the BRCA2 gene in sporadic ovarian cancer," Cancer Research, vol. 56, no. 16, pp. 3622-3625, 1996.

[7] S. Chen and G. Parmigiani, "Meta-analysis of BRCA1 and BRCA2 penetrance," Journal of Clinical Oncology, vol. 25, no. 11, pp. 1329-1333, 2007.

[8] D. Ford and D. F. Easton, "The genetics of breast and ovarian cancer," British Journal of Cancer, vol. 72, no. 4, pp. 805-812, 1995.

[9] M. Schutte, L. T. Da Costa, S. A. Hahn et al., "Identification by representational difference analysis of a homozygous deletion in pancreatic carcinoma that lies within the BRCA2 region," Proceedings of the National Academy of Sciences of the United States of America, vol. 92, no. 13, pp. 5950-5954, 1995.

[10] P. Tonin, P. Ghadirian, C. Phelan et al., "A large multisite cancer family is linked to BRCA2," Journal of Medical Genetics, vol. 32, no. 12, pp. 982-984, 1995.

[11] H. T. Lynch, R. E. Brand, C. A. Deters, T. G. Shaw, and J. F. Lynch, "Hereditary pancreatic cancer," Pancreatology, vol. 1, no. 5, pp. 466-471, 2001.

[12] A. C. Tersmette, G. M. Petersen, G. J. A. Offerhaus et al., "Increased risk of incident pancreatic cancer among first-degree relatives of patients with familial pancreatic cancer," Clinical Cancer Research, vol. 7, no. 3, pp. 738-744, 2001.

[13] D. M. Parkin, E. Laara, and C. S. Muir, "Estimates of the worldwide frequency of sixteen major cancers in 1980," International Journal of Cancer, vol. 41, no. 2, pp. 184-197, 1988.

[14] S. Raimondi, P. Maisonneuve, and A. B. Lowenfels, "Epidemiology of pancreatic cancer: an overview," Nature Reviews Gastroenterology and Hepatology, vol. 6, no. 12, pp. 699-708, 2009.

[15] C. Bosetti, P. Bertuccio, E. Negri, C. La Vecchia, M. P. Zeegers, and P. Boffetta, "Pancreatic cancer: overview of descriptive epidemiology," Molecular Carcinogenesis, vol. 51, no. 1, pp. 3-13, 2012.

[16] S. C. Larsson, L. Bergkvist, and A. Wolk, "Consumption of sugar and sugar-sweetened foods and the risk of pancreatic cancer in a prospective study," The American Journal of Clinical Nutrition, vol. 84, no. 5, pp. 1171-1176, 2006.

[17] P. Maisonneuve and A. B. Lowenfels, "Risk factors for pancreatic cancer: a summary review of meta-analytical studies," International Journal of Epidemiology, vol. 44, no. 1, pp. 186-198, 2015.

[18] T. P. Yeo, "Demographics, epidemiology, and inheritance of pancreatic ductal adenocarcinoma," Seminars in Oncology, vol. 42, no. 1, pp. 8-18, 2015.

[19] S. C. Larsson and A. Wolk, "Red and processed meat consumption and risk of pancreatic cancer: meta-analysis of prospective studies," British Journal of Cancer, vol. 106, no. 3, pp. 603-607, 2012.
[20] P. Ghadirian, J. Baillargeon, A. Simard, and C. Perret, "Food habits and pancreatic cancer: a case-control study of the Francophone community in Montreal, Canada," Cancer Epidemiology Biomarkers and Prevention, vol. 4, no. 8, pp. 895-899, 1995.

[21] A. F. S. Amaral, M. Porta, D. T. Silverman et al., "Pancreatic cancer risk and levels of trace elements," Gut, vol. 61, no. 11, pp. 1583-1588, 2012.

[22] WHO, WHO Guidelines: Water Quality and Health Strategy 2013-2020, WHO, 2016, http://www.who.int/water_sanitation_ health/publications/2013/water_quality_strategy.pdf.

[23] J. Ferlay, E. Steliarova-Foucher, J. Lortet-Tieulent et al., "Cancer incidence and mortality patterns in Europe: estimates for 40 countries in 2012," European Journal of Cancer, vol. 49, no. 6, pp. 1374-1403, 2013.

[24] A. Schulte, N. Pandeya, J. Fawcett et al., "Association between family cancer history and risk of pancreatic cancer," Cancer Epidemiology, vol. 45, pp. 145-150, 2016.

[25] J. P. Evans, W. Burke, R. Chen et al., "Familial pancreatic adenocarcinoma: association with diabetes and early molecular diagnosis," Journal of Medical Genetics, vol. 32, no. 5, pp. 330335, 1995.

[26] M. Wagner, C. Redaelli, M. Lietz, C. A. Seiler, H. Friess, and M. W. Büchler, "Curative resection is the single most important factor determining outcome in patients with pancreatic adenocarcinoma," British Journal of Surgery, vol. 91, no. 5, pp. 586-594, 2004.

[27] A. Cucchetti, G. Ercolani, G. Taffurelli et al., "A comprehensive analysis on expected years of life lost due to pancreatic cancer," Pancreatology, vol. 16, no. 3, pp. 449-453, 2016.

[28] D. P. Kelsen, R. Portenoy, H. Thaler, Y. Tao, and M. Brennan, "Pain as a predictor of outcome in patients with operable pancreatic carcinoma," Surgery, vol. 122, no. 1, pp. 53-59, 1997.

[29] C. Abaji, I. Cousineau, and A. Belmaaza, "BRCA2 regulates homologous recombination in response to DNA damage: implications for genome stability and carcinogenesis," Cancer Research, vol. 65, no. 10, pp. 4117-4125, 2005.

[30] S. K. Sharan, M. Morimatsu, U. Albrecht et al., "Embryonic lethality and radiation hypersensitivity mediated by Rad51 in mice lacking Brca2," Nature, vol. 386, no. 6627, pp. 804-810, 1997.

[31] D.-S. Lim and P. Hasty, "A mutation in mouse rad51 results in an early embryonic lethal that is suppressed by a mutation in p53," Molecular and Cellular Biology, vol. 16, no. 12, pp. 7133$7143,1996$.

[32] F. Connor, D. Bertwistle, P. Joseph Mee et al., "Tumorigenesis and a DNA repair defect in mice with a truncating Brca2 mutation," Nature Genetics, vol. 17, no. 4, pp. 423-431, 1997.

[33] L. S. Friedman, F. C. Thistlethwaite, K. J. Patel et al., "Thymic lymphomas in mice with a truncating mutation in BRCA2," Cancer Research, vol. 58, no. 7, pp. 1338-1343, 1998.

[34] M. E. Moynahan, A. J. Pierce, and M. Jasin, "BRCA2 is required for homology-directed repair of chromosomal breaks," Molecular Cell, vol. 7, no. 2, pp. 263-272, 2001.

[35] K. M. Murphy, K. A. Brune, C. Griffin et al., "Evaluation of candidate genes MAP2K4, MADH4, ACVR1B, and BRCA2 in familial pancreatic cancer: deleterious BRCA2 mutations in 17\%," Cancer Research, vol. 62, no. 13, pp. 3789-3793, 2002.

[36] M. Goggins, M. Schutte, J. Lu et al., "Germline BRCA2 gene mutations in patients with apparently sporadic pancreatic carcinomas," Cancer Research, vol. 56, no. 23, pp. 5360-5364, 1996. 
[37] L. Huang, C. Wu, D. Yu et al., "Identification of common variants in BRCA2 and MAP2K4 for susceptibility to sporadic pancreatic cancer," Carcinogenesis, vol. 34, no. 5, pp. 1001-1005, 2013.

[38] M. Goggins, R. H. Hruban, and S. E. Kern, "BRCA2 is inactivated late in the development of pancreatic intraepithelial neoplasia: evidence and implications," American Journal of Pathology, vol. 156, no. 5, pp. 1767-1771, 2000.

[39] M. Rowley, A. Ohashi, G. Mondal et al., "Inactivation of Brca2 promotes Trp53-associated but inhibits KrasG12D-dependent pancreatic cancer development in mice," Gastroenterology, vol. 140, no. 4, pp. 1303-1313, 2011.

[40] F. Skoulidis, L. D. Cassidy, V. Pisupati et al., "Germline Brca2 heterozygosity promotes $\mathrm{Kras}^{\mathrm{G12D}}$-driven carcinogenesis in a murine model of familial pancreatic cancer," Cancer Cell, vol. 18, no. 5, pp. 499-509, 2010.

[41] J. P. Struewing, P. Hartge, S. Wacholder et al., "The risk of cancer associated with specific mutations of BRCA1 and BRCA2 among Ashkenazi Jews," New England Journal of Medicine, vol. 336, no. 20, pp. 1401-1408, 1997.

[42] C. Oddoux, J. P. Struewing, C. M. Clayton et al., “The carrier frequency of the BRCA2 6174delT mutation among Ashkenazi Jewish individuals is approximately 1\%," Nature Genetics, vol. 14, no. 2, pp. 188-190, 1996.

[43] S. A. Hahn, B. Greenhalf, I. Ellis et al., "BRCA2 germline mutations in familial pancreatic carcinoma," Journal of the National Cancer Institute, vol. 95, no. 3, pp. 214-221, 2003.

[44] F. J. Couch, M. R. Johnson, K. G. Rabe et al., "The prevalence of BRCA2 mutations in familial pancreatic cancer," Cancer Epidemiology Biomarkers and Prevention, vol. 16, no. 2, pp. 342346, 2007.

[45] A. K. Rustgi, "Familial pancreatic cancer: genetic advances," Genes and Development, vol. 28, no. 1, pp. 1-7, 2014.

[46] T. A. Kunkel and D. A. Erie, "DNA mismatch repair," Annual Review of Biochemistry, vol. 74, pp. 681-710, 2005.

[47] J. Jiricny, “The multifaceted mismatch-repair system," Nature Reviews Molecular Cell Biology, vol. 7, no. 5, pp. 335-346, 2006.

[48] X. Dong, Y. Li, K. R. Hess, J. L. Abbruzzese, and D. Li, "DNA mismatch repair gene polymorphisms affect survival in pancreatic cancer," Oncologist, vol. 16, no. 1, pp. 61-70, 2011.

[49] N. Habbe, P. Langer, M. Sina-Frey, and D. K. Bartsch, "Familial pancreatic cancer syndromes," Endocrinology and Metabolism Clinics of North America, vol. 35, no. 2, pp. 417-430, 2006.

[50] G. Luo, Y. Lu, K. Jin et al., "Pancreatic cancer: BRCA mutation and personalized treatment," Expert Review of Anticancer Therapy, vol. 15, no. 10, pp. 1223-1231, 2015.

[51] Z. H. Siddik, "Cisplatin: mode of cytotoxic action and molecular basis of resistance," Oncogene, vol. 22, no. 47, pp. 7265-7279, 2003.

[52] G. R. Oliver, E. Sugar, D. Laheru, and L. A. Diaz, "Family history of cancer and sensitivity to platinum chemotherapy in pancreatic adenocarcinoma," in Proceedings of the Gastrointestinal Cancers Symposium, abstract 180, 2010.

[53] A. Sonnenblick, L. Kadouri, L. Appelbaum et al., "Complete remission, in BRCA2 mutation carrier with metastatic pancreatic adenocarcinoma, treated with cisplatin based therapy," Cancer Biology and Therapy, vol. 12, no. 3, pp. 165-168, 2011.

[54] B. Tran, G. Zogopoulos, A. Borgida, S. Holter, S. Gallinger, and M. J. Moore, "Platinum-based chemotherapy (pt-chemo) in pancreatic adenocarcinoma (pc) associated with brca mutations: a translational case series," Journal of Clinical Oncology (ASCO Meeting 2012), vol. 30, abstract 217, 2012.
[55] T. Golan, Z. S. Kanji, R. Epelbaum et al., "Overall survival and clinical characteristics of pancreatic cancer in BRCA mutation carriers," British Journal of Cancer, vol. 111, no. 6, pp. 1132-1138, 2014.

[56] N. Waddell, M. Pajic, A.-M. Patch et al., "Whole genomes redefine the mutational landscape of pancreatic cancer," Nature, vol. 518, no. 7540, pp. 495-501, 2015.

[57] J.-M. Lee, J. A. Ledermann, and E. C. Kohn, "PARP inhibitors for BRCA1/2 mutation-associated and BRCA-like malignancies," Annals of Oncology, vol. 25, no. 1, Article ID mdt384, pp. 32-40, 2014.

[58] N. McCabe, C. J. Lord, A. N. J. Tutt, N. M. B. Martin, G. C. M. Smith, and A. Ashworth, "BRCA2-deficient CAPAN-1 cells are extremely sensitive to the inhibition of poly (ADP-Ribose) polymerase: an issue of potency," Cancer Biology and Therapy, vol. 4, no. 9, pp. 934-936, 2005.

[59] L. Porcelli, A. E. Quatrale, P. Mantuano et al., "Optimize radiochemotherapy in pancreatic cancer: PARP inhibitors a new therapeutic opportunity," Molecular Oncology, vol. 7, no. 3, pp. 308-322, 2013.

[60] Y. Wang, Y. Kuramitsu, K. Tokuda et al., "Gemcitabine induces poly (ADP-ribose) polymerase-1 (PARP-1) degradation through autophagy in pancreatic cancer," PLoS ONE, vol. 9, no. 10, Article ID e109076, 2014.

[61] D. A. Jacob, M. Bahra, J. M. Langrehr et al., "Combination therapy of poly (ADP-ribose) polymerase inhibitor 3aminobenzamide and gemcitabine shows strong antitumor activity in pancreatic cancer cells," Journal of Gastroenterology and Hepatology, vol. 22, no. 5, pp. 738-748, 2007.

[62] M. A. Lowery, D. P. Kelsen, Z. K. Stadler et al., "An emerging entity: pancreatic adenocarcinoma associated with a known brca mutation: clinical descriptors, treatment implications, and future directions," Oncologist, vol. 16, no. 10, pp. 1397-1402, 2011.

[63] M. J. Pishvaian, H. Wang, T. Zhuang et al., "A phase I/II study of ABT-888 in combination with 5-fluorouracil (5-FU) and oxaliplatin $(\mathrm{Ox})$ in patients with metastatic pancreatic cancer (MPC)," Journal of Clinical Oncology, vol. 31, supplement 4, abstract 147, 2013.

[64] E. M. O’Reilly, M. A. Lowery, M. F. Segal et al., "Phase IB trial of cisplatin $(\mathrm{C})$, gemcitabine $(\mathrm{G})$, and veliparib $(\mathrm{V})$ in patients with known or potential BRCA or PALB2-mutated pancreas adenocarcinoma (PC)," Journal of Clinical Oncology, vol. 32, no. 5s, supplement, abstract 4023, 2014.

[65] A. V. Biankin, N. Waddell, K. S. Kassahn et al., "Pancreatic cancer genomes reveal aberrations in axon guidance pathway genes," Nature, vol. 491, no. 7424, pp. 399-405, 2012.

[66] D. D. Von Hoff, T. J. Ervin, F. P. Arena et al., "Results of a randomized phase III trial (IMPaCT) of weekly nab-paclitaxel plus gemcitabine versus gemcitabine alone for patients with metastatic adenocarcinoma of the pancreas with PET and CA19-9 correlates," in Proceedings of the ASCO Annual Meeting, abstract 4005, 2013.

[67] L. A. Chantrill, A. M. Nagrial, C. Watson et al., "Precision medicine for advanced pancreas cancer: the individualized molecular pancreatic cancer therapy (IMPaCT) Trial," Clinical Cancer Research, vol. 21, no. 9, pp. 2029-2037, 2015.

[68] W. Sakai, E. M. Swisher, B. Y. Karlan et al., "Secondary mutations as a mechanism of cisplatin resistance in BRCA2-mutated cancers," Nature, vol. 451, no. 7182, pp. 1116-1120, 2008. 
[69] U. Nöthlings, L. R. Wilkens, S. P. Murphy, J. H. Hankin, B. E. Henderson, and L. N. Kolonel, "Meat and fat intake as risk factors for pancreatic cancer: the multiethnic cohort study," Journal of the National Cancer Institute, vol. 97, no. 19, pp. 14581465, 2005. 


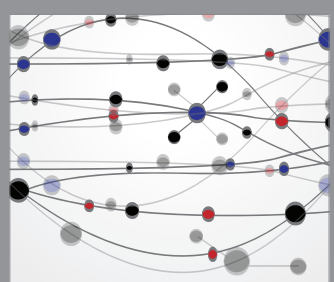

The Scientific World Journal
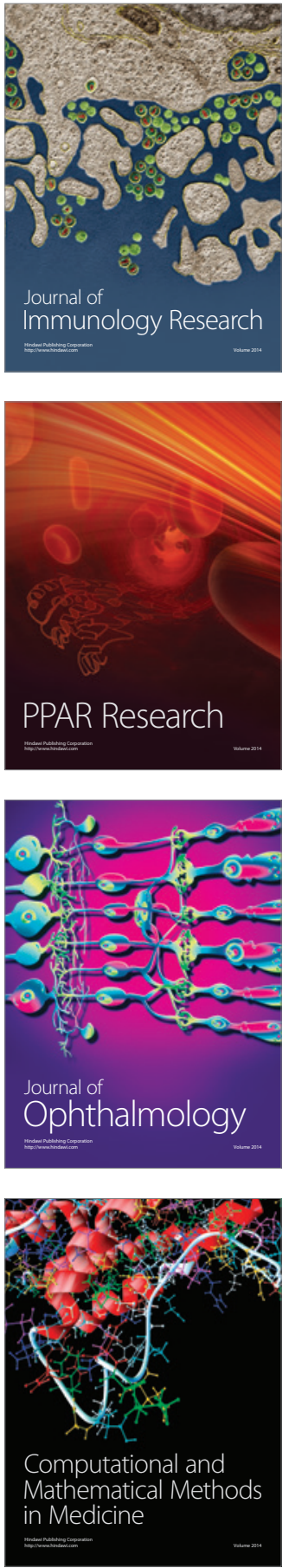

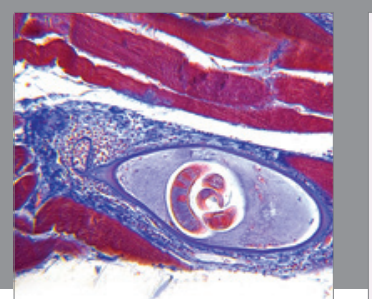

Gastroenterology Research and Practice

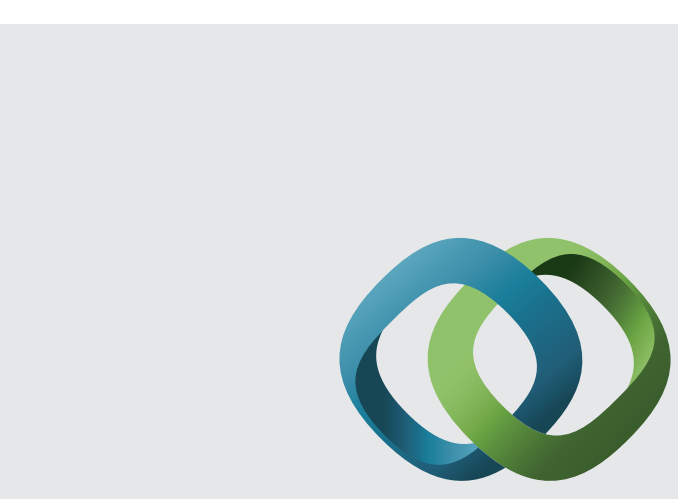

\section{Hindawi}

Submit your manuscripts at

http://www.hindawi.com
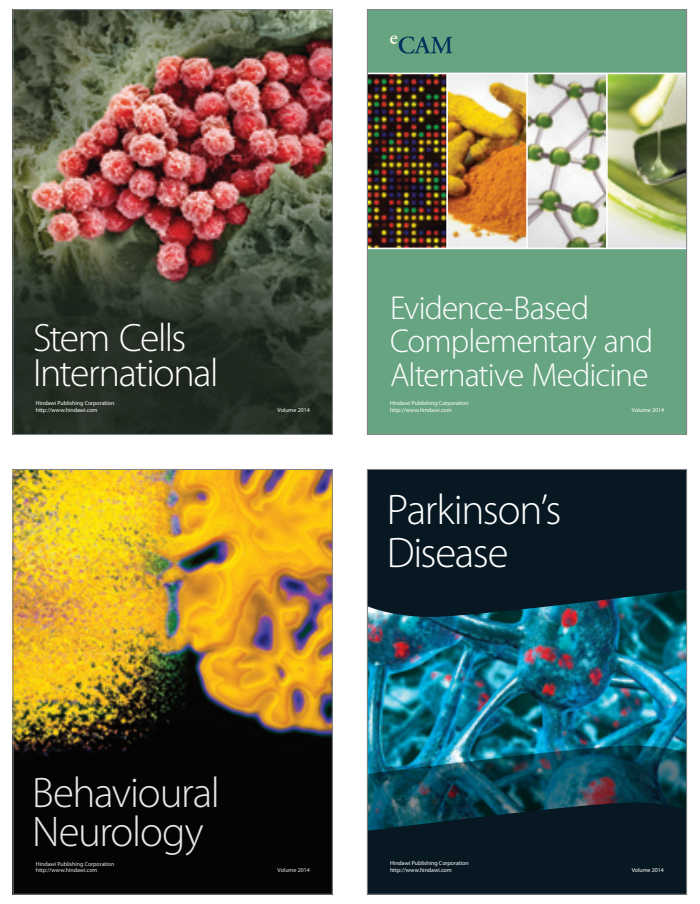
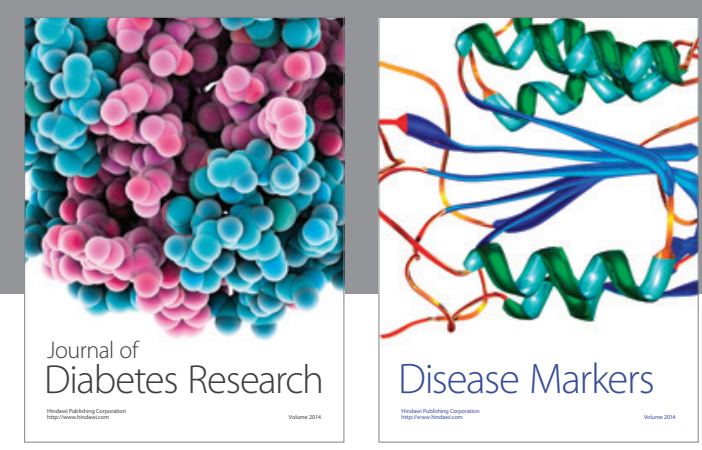

Disease Markers
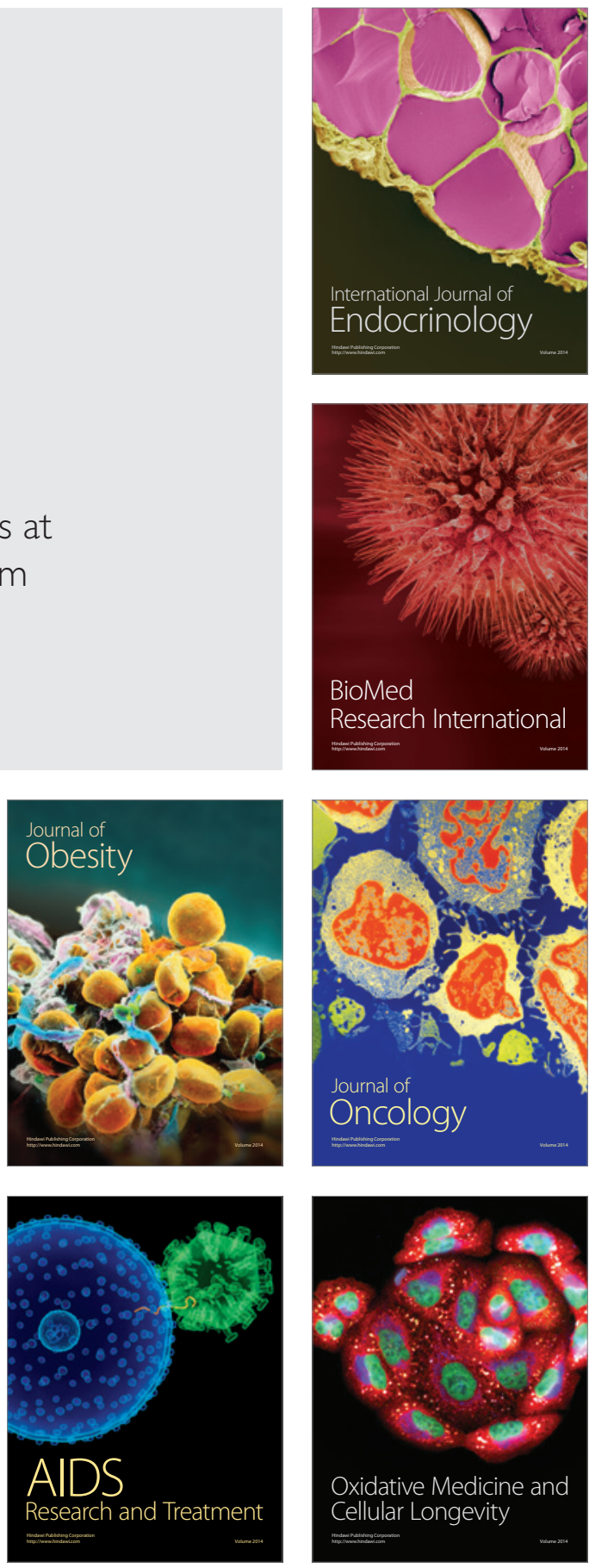